\title{
Aplicação de Algoritmos Genéticos Paralelos na Simulação da Secagem de Grãos de Soja
}

\author{
Maurício dos Santos Dessuy ${ }^{1}$, Manuel Osório Binello ${ }^{1}$, Edson L. Padoin ${ }^{1}$ \\ ${ }^{1}$ Universidade Reg. do Noroeste do Estado do Rio G. do Sul (UNIJUI) - Ijuí - RS - Brasil \\ mauriciodessuy@hotmail.com, manuel.binelo@unijui.edu.br, padoin@unijui.edu.br
}

\begin{abstract}
Resumo. As pesquisas que envolvem a experimentação com os grãos de soja demandam altos custos e o emprego de equipamento de alta qualidade. Por conta disto simulações computacionais são cada vez mais utilizadas para replicar os problemas reais em um ambiente digital. Com isto foi desenvolvido uma pesquisa que visa determinar os parâmetros por meio da aplicação de algoritmos genéticos na simulação do processo evolutivo das espécies. Uma versão paralela foi implementada utilizando o YADE com até 12 threads que aplicam heurísticas para encontrar os parâmetros que resultam em uma solução. Os resultados iniciais da paralelização da aplicação apresentaram ganhos de até 9,8 vezes comparado aos testes com uma versão sequencial.
\end{abstract}

\section{Introdução}

Pesquisas quem envolvem grãos de soja apresentam muitas variáveis que precisam ser analisadas. Em seus principais espécimes podem variar conforme o tipo da semente, o nível de umidade do grão, o tamanho, o peso, dentre outros aspectos. Tendo como base a grande variedade atualmente comercializada, obter suas medidas e características torna-se um processo custoso e complexo, uma vez que é necessário a utilização de equipamentos de laboratório de alta qualidade que demandam de elevados tempos para se obter os resultados precisos. Nesse contexto, realizar uma busca destas propriedades por meio de experimentos físicos não é uma tarefa viável, uma vez que a solução ótima pode levar anos para ser descoberta. Assim, faz-se necessário a aplicação de técnicas inteligentes para obtenção de resultados mais precisos, dentre elas, a aplicação de algoritmos genéticos tem sido utilizada e logrado respostas adequadas.

Dentre as etapas do cultivo da soja, o processo de secagem dos grãos apresenta uma natureza discreta. Em seu manejo, esta etapa apresenta diversos tipos de problemas nos silos de secagem, como por exemplo a ocorrência de incêndios, que são causados por grãos que receberam rajadas de ar quente por muito tempo em seu processo de secagem [da Silva 2005]. Assim, para que este problema possa ser simulado computacionalmente, primeiramente é necessário determinar as propriedades físicas dos grãos de soja. Para isto foi então adotado um algoritmo genético para determinação indireta destas propriedades permitindo então a execução de simulações computacionais de secagem além de armazenamento, movimentação e processamento de grãos.

Nesse sentido, este artigo apresenta os resultados para paralelização do algoritmo genético aplicado na determinação indireta de parâmetros das propriedades do grão da soja. O restante do trabalho está assim organizado. A Seção 2 discute os trabalhos relacionados. A Seção 3 apresenta a paralelização do algoritmo genético. A Seção 4 descreve a metodologia aplicada na implementação e o ambiente de execução utilizado na realização dos testes. Resultados são discutidos na Seção 5, seguidos das conclusões e trabalhos futuros. 


\section{Trabalhos Relacionados}

O Método dos Elementos Discretos (MED) é comumente utilizado como um modelo matemático para representar a interação entre partículas representadas por esferas. E sua implementação, em cada partícula simulada são aplicadas as forças e as interações presentes no modelo, simulando assim a movimentação mecânica nas partículas presentes no sistema [Khatchatourian et al. 2014].

Para que a simulação possa diferenciar objetos maleáveis de objetos rígidos o MED utilizada o módulo de Young, ao qual é uma medida baseada na Lei de Hooke que define o grau de deformação que o objeto pode sofrer de acordo com a força que é aplicada a ele. Assim, com o intuito de simular torções nas partículas da simulação o MED implementa uma propriedade chamada de módulo de cisalhamento, ao qual sua função é promover um deslocamento lateral conforme é aplicado uma força na direção do elemento [Cossolino and Pereira 2010].

Nesse módulo de Young é então definido o grau de deformação longitudinal de um objeto, o módulo de Poison a partir da razão entre as forças longitudinais e as forças transversais obtém-se um valor sem dimensões que define o coeficiente de deformação transversal do objeto[Mentges 2019].

Muitas pesquisas tem utilizado algoritmos genéticos na solução de problemas. Vlavsic et. al. aprimoraram o desempenho dos algoritmos genéticos utilizando técnicas de inicialização de populações. Neste trabalho os autores desenvolveram os métodos DEX, DGP, SGP e CMB para inicialização da população e realizaram uma comparação com o método padrão que realiza a geração de forma aleatória. Os testes demonstraram que o método CMB apresentam o maior desempenho [Vlašić et al. 2019].

Os autores Haustein et. al. desenvolveram uma pesquisa focada na implementação de um modelo de deformação de partículas. Com este novo modelo é possível incrementar as simulações envolvendo a soja pois em seu estado de armazenamento os grãos que ocupam as posições mais a baixo do monte estão a todo momento sofrendo a deformidade em decorrência do alto peso sob seus corpos [Haustein et al. 2017].

\section{Proposta}

Algoritmos genéticos são um modelo de algoritmo que tem como objetivo convergir para uma solução de um determinado problema. Para alcançar uma solução, ótima ou não, são definidos alguns elementos obrigatórios, como a população de indivíduos, o cruzamento de indivíduos, a mutação dos indivíduos e o cálculo da taxa de aptidão (fitness) de cada indivíduo [Devillers 1996].

A principal chave para o sucesso de um algoritmo genético é a definição de uma função de aptidão para qual o algoritmo deve convergir. Nesse contexto, para a definição desta função foi realizada uma série de experimentos físicos em um aparato físico. Após o desenvolvimento dos experimentos físicos foi realizada a simulação computacional utilizando os diversos parâmetros possíveis.

\section{Metodologia}

A experimentação física tende a ser um processo complicado uma vez que torna-se necessário a construção de um aparato para que o experimento possa ser executado. Nesse contexto a ferramenta Yet Another Dynamic Engine (Yade), desenvolvida na linguagem C++, permite o 
desenvolvimento de simulações computacionais provendo um ambiente para a criação de estruturas e partículas. Uma vez criado o ambiente, nele podem ser realizados simulações com o método dos elementos discretos [Mentges 2019]. Além disso, o Yade permite tembém a implementação de outros tipos de metodologias, como por exemplo o Método dos Elementos Finitos, o Smoothed Particle Hydrodynamics (SPH) e o Lattice Geometric Model (LGM). Permitindo assim uma gama maior de possibilidades de uso ao usuário [Lima 2014].

Uma versão paralela foi implementada que faz a criação do grão de soja e das estruturas necessárias para recriar o experimento físico. O framework Yade foi utilizado para criar as estruturas fixas em um determinado espaço permitindo a realização da simulação computacional com um tubo de acrílico, uma parede de madeira e uma esfera para representar o grão de soja.

Com a estrutura da simulação montada foi possível complementar o código para que ele servisse para o algoritmo genético. Os testes foram realizados em um servidor com um processador Intel Xeon E5-4610 1.80GHz com 12 cores rodando sistema operacional Ubuntu 18.04 com kernel versão 4.4.33.

\section{Resultados}

Como pode ser visto na Figura 2, inicialmente os indivíduos apresentaram-se de forma totalmente espalhada, devido ao fato de que a população inicial do algoritmo genético é gerada de forma totalmente aleatória. Porém ao passar das gerações foi possível notar que os indivíduos foram convergindo para os pontos 0,25 no coeficiente de Poison e 0,15 no coeficiente de dispersão de forças, ao qual é o campo onde mais se aproxima dos resultados desejados. Outro ponto interessante é que o fator de mutação auxilia muito na busca por resultados em outro ponto de máximo, pois mesmo na geração de número 100 é possível notar que existem elementos fora deste ponto de concentração.

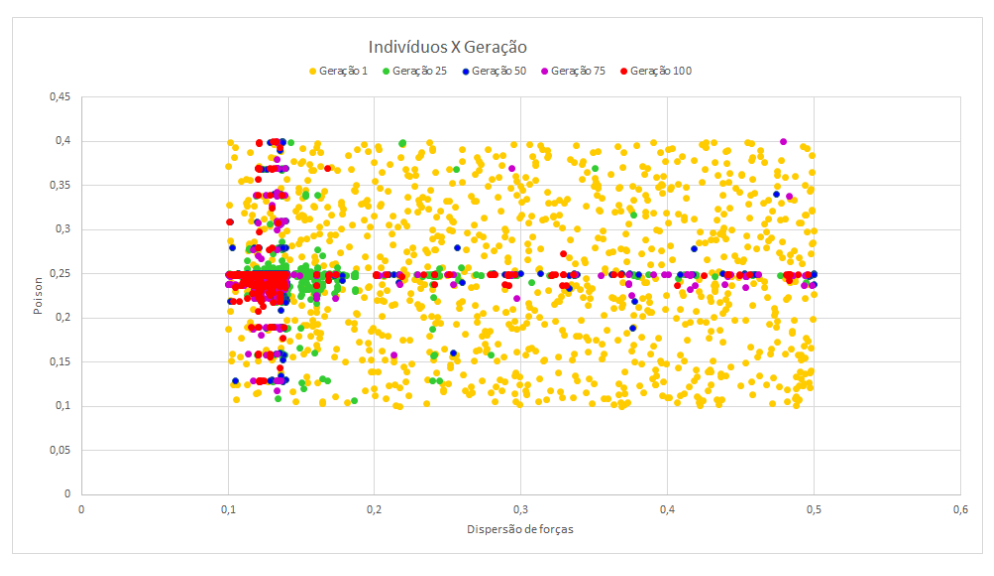

Figura 1. Gráfico da evolução dos indivíduos pelas gerações.

Na simulação a esfera levou cerca de 1,5 segundos para que entrasse no estado de repouso. Com a paralelização da aplicação conseguiu-se reduzir o tempo de execução de 2004, 6 para 204, 8 segundos, o que representa um speedup de 9, 8 quando executado com 12 cores do equipamento.

\section{Conclusões e trabalhos futuros}

Este trabalho apresentou uma análise da paralelização do algoritmo genético aplicado na determinação indireta de parâmetros das propriedades das esferas (grão da soja). Após tes- 


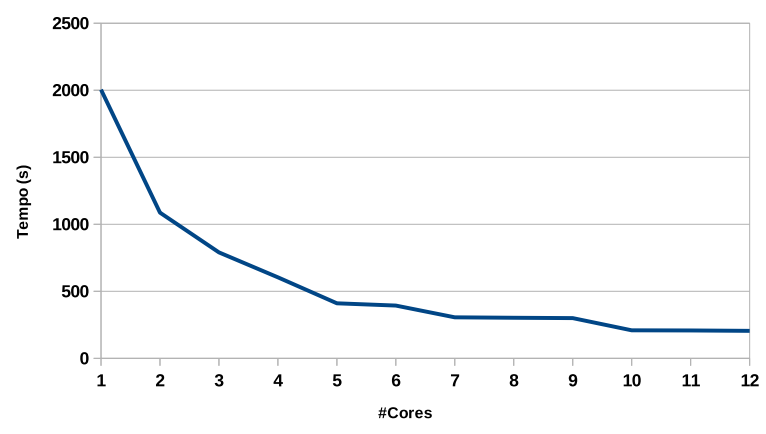

Figura 2. Gráfico de tempo de execução por número de cores.

tes físicos e simulação computacional, é possível inferir que o algoritmo genético apresentou um bom fator de busca por soluções, além de apresentar um bom desempenho se comparado a uma solução de força bruta, visto que seria necessário anos de execução do algoritmo para testar todo o conjunto de possíveis parâmetros. Os parâmetros encontrados possuíam um grau de especifidade muito alto visto que tanto o coeficiente de poisson quanto o coeficiente de dissipação de forças possuíam valores decimais de cerca de quinze casas.

Com a versão paralela implementada será possível obter outros tipos de propriedades. Como futuros trabalhos, pretende-se realizar pesquisas com o algoritmo genético na busca outros parâmetros para então serem utilizados no treinamento de uma rede neural, ao qual terá a função de predizer a solução de acordo com os parâmetros informados.

\section{Referências}

Cossolino, L. C. and Pereira, A. H. A. (2010). Módulos elásticos: visão geral e métodos de caracterização. Informativo Técnico Científico. Disponível em: http://www. atcp. com. br/imagens/produtos/sonelastic/artigos/RT03-ATCP. pdf.

da Silva, L. C. (2005). Secagem de grãos. Boletim Técnico: AG, 4(05).

Devillers, J. (1996). Genetic algorithms in computer-aided molecular design. In Genetic Algorithms in Molecular Modeling, pages 1-34. Elsevier.

Haustein, M., Gladkyy, A., and Schwarze, R. (2017). Discrete element modeling of deformable particles in yade. SoftwareX, 6:118-123.

Khatchatourian, O. A., Binelo, M. O., and de Lima, R. F. (2014). Simulation of soya bean flow in mixed-flow dryers using dem. Biosystems engineering, 123:68-76.

Lima, R. F. d. (2014). Modelagem matemática do escoamento de grãos de soja em um secador com fluxo misto usando o método dos elementos discretos.

Mentges, M. (2019). Modelagem matemática e simulação computacional do fluxo de grãos com presença de partículas de impurezas em secadores.

Vlašić, I., urasević, M., and Jakobović, D. (2019). Improving genetic algorithm performance by population initialisation with dispatching rules. Computers \& Industrial Engineering, 137:106030. 